\title{
Effects of milling and annealing on formation and structural characterization of nanocrystalline intermetallic compounds from $\mathrm{Ni}$-Ti elemental powders
}

\author{
Morteza Ghadimi a,*, Ali Shokuhfar ${ }^{\text {a }}$, Hamid Reza Rostami ${ }^{\text {b }}$, Mohammad Ghaffari ${ }^{\mathrm{c}}$ \\ a Advanced Materials and Nanotechnology Research Center, Faculty of Mechanical Engineering, K.N. Toosi University of Technology, P.O. Box: 19395-1999, Tehran, Iran \\ ${ }^{\mathrm{b}}$ Faculty of Materials Science and Engineering, Science E Research Branch, Islamic Azad University, P.O. Box: 14515-775, Tehran, Iran \\ c UNAM - Institute of Materials Science and Nanotechnology, Bilkent University, Ankara 06800, Turkey
}

\section{A R T I C L E I N F O}

\section{Article history:}

Received 2 March 2012

Accepted 22 April 2012

Available online 27 April 2012

\section{Keywords:}

Shape memory materials

Nanocrystalline materials

Intermetallic alloys and compounds

Phase transformation

Electron microscopy

$\mathrm{X}$-ray techniques

\begin{abstract}
A B S T R A C T
Nickel and Titanium elemental powders with a nominal composition $\mathrm{Ni}-50$ at.\%Ti were mechanical alloyed in a planetary high-energy ball mill in different milling conditions $(5,10,20,40$ and $60 \mathrm{~h}$ ). The investigation revealed that increasing milling time leads to a reduction in crystallite size, and after $60 \mathrm{~h}$ of milling, the Ti dissolved in Ni lattice and NiTi (B2) phase was obtained. With milling time, morphology of pre-alloyed powders changed from lamella to globular. Annealing of as-milled powders at $1173 \mathrm{~K}$ for $900 \mathrm{~s}$ led to formation of nanocrystalline NiTi (B19'), grain growth and release of internal strain. The results indicated that this technique is a powerful and high productive process for preparing NiTi intermetallic compound with nanocrystalline structure and appropriate morphology.
\end{abstract}

(c) 2012 Elsevier B.V. All rights reserved.

\section{Introduction}

NiTi shape memory compounds are being used in a variety of medical and engineering purposes owing to unique shape memory effect (SME) and superior superelasticity with excellent corrosion resistance, good biocompatibility and wear resistance. Shape memory behavior of this material is due to thermoelastic martensitic transformation from high temperature B2 (austenite) to low temperature B19' (martensite) phase [1-3]. Shape memory materials are made by well-known methods related to melting and casting. These approaches are high energy consuming and imply difficulties in control of the processed alloy composition [1]. In order to obtain inexpensive products, researchers have been focused on nearly synthesis process in efforts to establish to optimum production route and to obtain materials with improved properties.

Mechanical alloying (MA) is a versatile and widely used technique for preparation of intermetallic compounds, because of its advantages including high yield, low cost, and ease of control of particle size and shape. Moreover, in this process, the reduction of particle size to nano-scale results in nanocrystalline materials with homogeneous structures. In this method, high-energy collisions of the balls and the vial lead to repeated cold welding and fracturing of powders, and finally preparation of alloyed powders [4-6].

\footnotetext{
* Corresponding author. Tel.: +98 912 8040281; fax: +98 2188677274.

E-mail addresses: ghadimi1985@gmail.com, mghadimi@sina.kntu.ac.ir (M. Ghadimi).
}

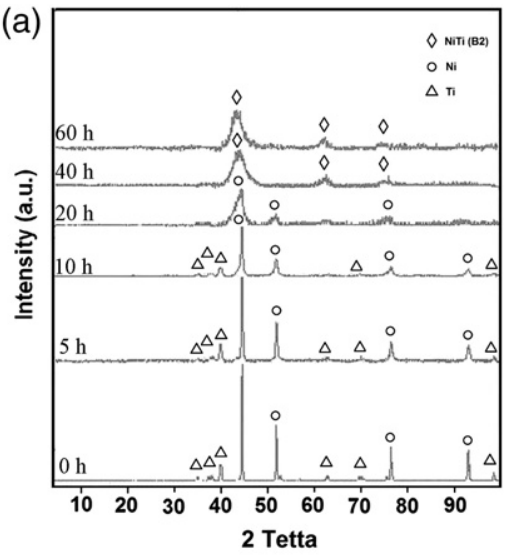

(b)

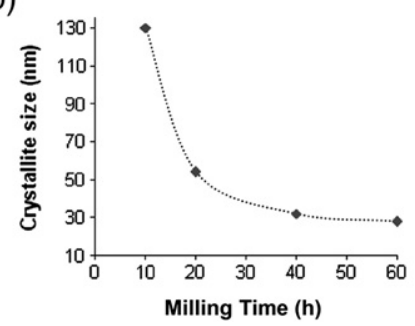

Fig. 1. (a) XRD patterns of mixture powders at several milling times and (b) Crystallite size of mixture powders as a functional of milling time. 

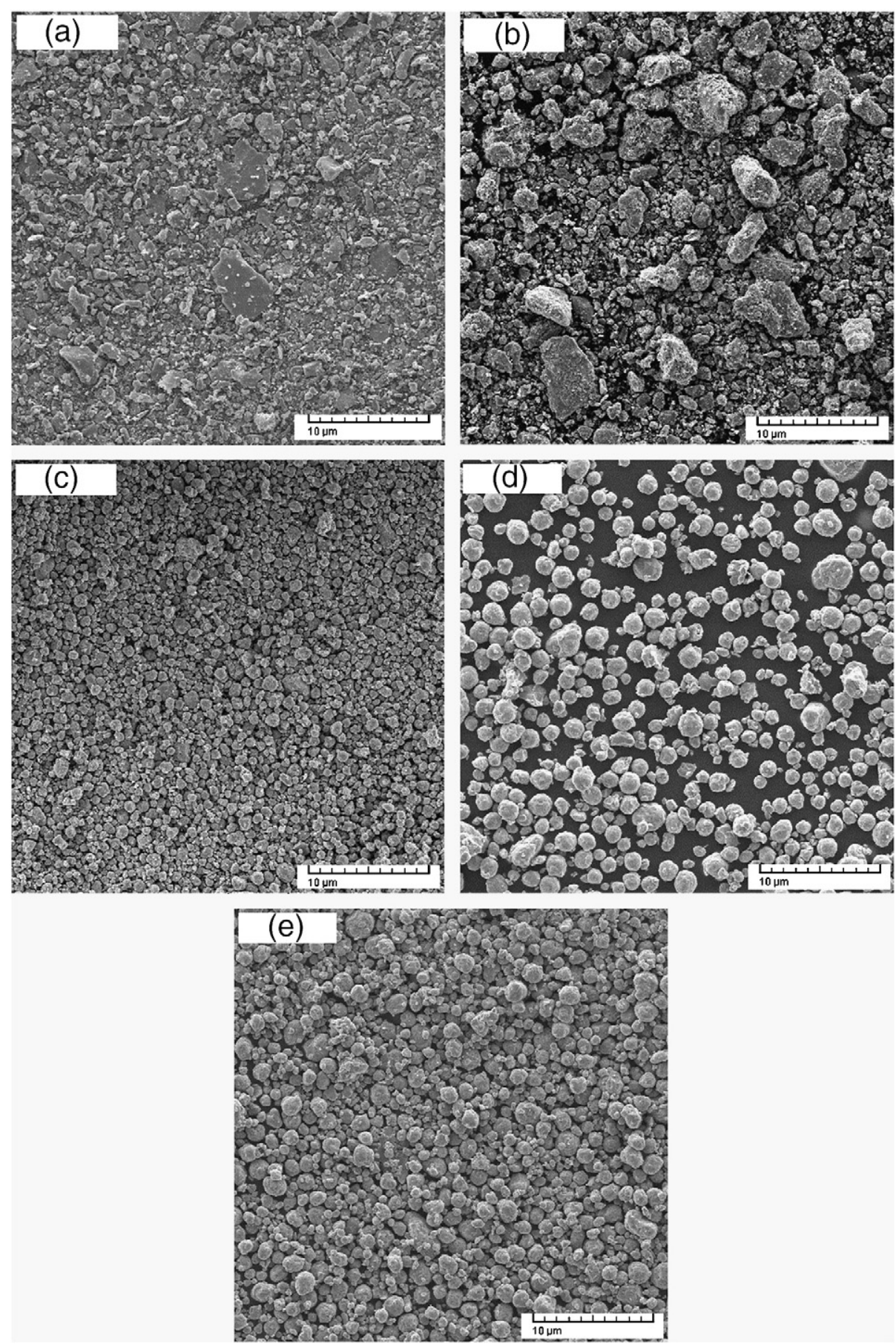

Fig. 2. SEM micrographs of milled powders after different milling times (a) 5 h; (b) 10 h; (c) 20 h; (d) 40 h and (e) 60 h.

The present paper reports the synthesis and investigation of nanocrystalline intermetallic compounds in Ni-Ti system by MA and further heat treatment. Meanwhile, the effects of milling time and annealing process on grain size, morphological changes and phase compositions were studied.

\section{Material and methods}

The elemental powders of $\mathrm{Ni}$ (99.9\% purity) and $\mathrm{Ti}$ (99.5\% purity) with a mean particle size of about $10 \mu \mathrm{m}$ and nominal composition $\mathrm{Ni}-50$ at.\%Ti were mechanically alloyed in a planetary high energy ball mill (Fritch P6) using hardened stainless steel balls (50 balls with diameter of $10 \mathrm{~mm})$ and vial $(225 \mathrm{ml})$ in different milling times. A ball to powder weight ratio (BPR) of 10:1 was maintained and milling speed was adjusted to $300 \mathrm{rpm}$. The milling was carried out under a protective argon atmosphere to avoid oxidation and atmospheric contamination of powders.

After certain milling conditions (5, 10, 20, 40 and $60 \mathrm{~h}$ ), a small amount of milled powder was collected for structural evaluation through XRD analysis with Xpert Philips diffractometer using a Fe filler and $\mathrm{Cu} K \alpha$ radiation $(\lambda=0.15406 \mathrm{~nm})$ at a voltage and electrical current of $40 \mathrm{kV}$ and $30 \mathrm{~mA}$, respectively. The evaluation of morphology and study of particle size were performed via scanning electron microscopy (SEM) at a voltage of $15 \mathrm{kV}$ in a Vega $\odot$ Tescan. After $60 \mathrm{~h}$ milling, the as-milled powders were sealed in quartz tubes under high vacuum and annealed at $1173 \mathrm{~K}$ for $900 \mathrm{~s}$ followed by water-quenching in order to study the phase transition occurring during annealing. 


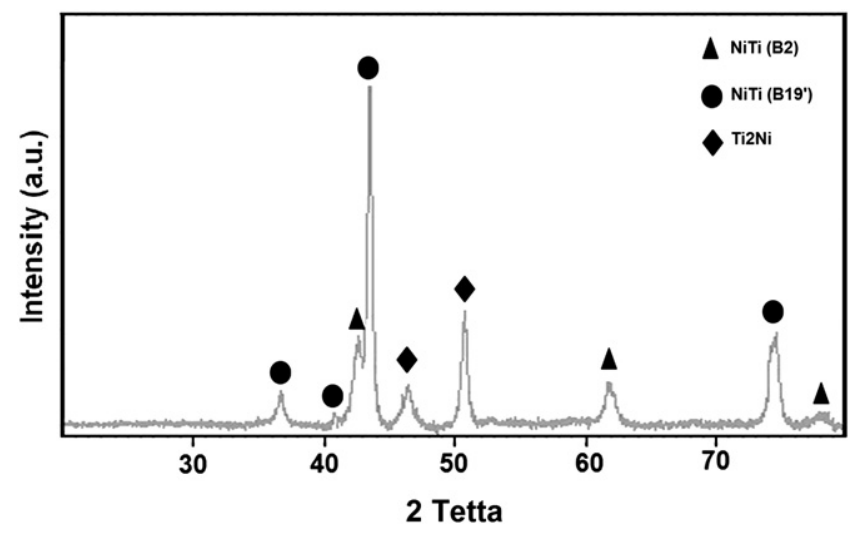

Fig. 3. XRD patterns of powders after $60 \mathrm{~h}$ milling $+900 \mathrm{~s}$ annealing.

\section{Results and discussion}

\subsection{XRD analysis}

XRD diffraction profiles of milled powders at various milling times are shown in Fig. 1a. According to this figure, the peaks related to raw materials can be detected in starting materials. With milling time, there is broadening of the diffraction peaks and a significant decrease in the line intensity of all diffraction peaks. In addition, the position of the diffraction lines corresponding to Ni moved to lower angles. The weakening of $\mathrm{Ni}$ and $\mathrm{Ti}$ peaks and the shift of $\mathrm{Ni}$ peaks toward lower angles indicated that $\mathrm{Ti}$ atoms diffused into the Ni matrix and lattice parameters of $\mathrm{Ni}$ increased. The peaks related to Ti disappeared $20 \mathrm{~h}$ of milling. On the other hand, there was no evidence for existence of $\mathrm{Ti}$ in mixture compounds. In fact, the Ti dissolved completely in the Ni lattice. After $60 \mathrm{~h}$ milling, the Ni peaks vanished completely and only broadened NiTi (B2) peaks with a body centered cubic structure were identified. The broadening of the NiTi peaks was considered to be due to the refinement effect of crystallite size. The crystallite sizes of compounds were calculated using XRD peak broadening and Williamson-Hall formula as follows [6]:

$\sqrt{\mathrm{B}_{\mathrm{i}}^{2}-\mathrm{B}_{0}^{2}} \cos \theta=0.89 \lambda / \mathrm{d}+2 \mathrm{e} \sin \theta$

where $B_{i}$ is the peak full-width at the half of the maximum intensity of XRD patterns (FWHM), $B_{0}$ is the correction factor for instrument broadening, $\theta$ is the Bragg angle, $\lambda$ is the wavelength of the X-ray used, $\mathrm{d}$ is the crystallite size and $\mathrm{e}$ is the lattice strain.

Fig. 1b shows the variations of crystallite sizes versus milling time. Increasing of milling time led to reduction in crystallite size that is mainly due to severe deformation of powders during ball milling. The other reason might be increased probability of nucleation sites during crystallization, provided by higher defect densities [4]. At the onset of milling process, crystallite size decreased dramatically and lattice strain increased. However for longer milling times, grain size almost did not change and became constant due to the balance between rate of cold welding and fracturing of powders particles [5]. After $60 \mathrm{~h}$ of milling, crystallite size of milled powders reduced down to $24 \mathrm{~nm}$.

\subsection{SEM observation}

Fig. 2 presents the morphology of milled powders after several milling time. At the beginning of milling, a lamellar structure was observed, because of continuous cold welding between laminate during ball milling of ductile particle has occurred, but the spaces between these lamellae are high. Increasing milling time to $10 \mathrm{~h}$, the laminated structure becomes discontinuous and the thickness of the layers decreases. On further milling, the size of particles decreases because, increase in brittleness leads to formation of smaller particles with granular shape. Meanwhile, the distribution of particle morphology and particle size becomes narrower. On the other hand, the repeated processes of cold welding and fracturing result in generation of agglomerations consisting of nanosized $\mathrm{Ni}$ and Ti particles.

\subsection{Annealing}

Fig. 3 displays the XRD spectra of milled and annealed powders at $1173 \mathrm{~K}$ for $900 \mathrm{~s}$. As can be seen the annealing process induced several diffraction peaks and led to formation of NiTi (B19' with a body monoclinic structure) and $\mathrm{Ti}_{2} \mathrm{Ni}$ phases. Since the annealing temperature was higher than $0.6 \mathrm{~T}_{\mathrm{m}}\left(\mathrm{T}_{\mathrm{m}}\right.$ : melting temperature of NiTi), recrystallization occurred and caused grain growth due to release of internal strains. The crystallite size increases from initial value to $59 \mathrm{~nm}$.

\section{Conclusions}

(1) MA of pure elemental $\mathrm{Ni}$ and Ti powder mixtures in a planetary high-energy ball mill led to solution of Ti into B2 structure and preparation of NiTi intermetallic phase with nanocrystalline structure and homogeneous configuration.

(2) The annealing of as-milled powders resulted in production of nanostructured NiTi (B19') phase.

(3) The XRD examinations and SEM observations revealed that the mechanical alloying fallowed by annealing is a useful, cost effective and high productive method for preparing NiTi intermetallic compounds with appropriate structures and suitable morphologies.

\section{References}

[1] Otsuka K, Ren X. Physical metallurgy of Ni-Ti-based shape memory alloys. Prog Mater Sci 2005;50:511-678.

[2] Da Silva EP. Calorimetric observations on an NiTi alloy exhibiting two-way memory effect. Mater Lett 1999;38:341-3.

[3] Ballas M, Li Z, Ilegbusi OJ. Modeling reaction front propagation and porosity in pressure-assisted combustion synthesis of porous NiTi Intermetallics. J Mater Eng Perform 2012;21:298-307.

[4] Suryanarayana C. Mechanical alloying and milling. New York: Marcel Dekke; 2004.

[5] Ghaffari M, Tan PY, Oruc ME, Tan OK, Tse MS, Shannon M. Effect of ball milling on the characteristics of nano structure $\mathrm{SrFeO}_{3}$ powder for photocatalytic degradation of methylene blue under visible light irradiation and its reaction kinetics. Catalysis Today 2011;161:70-7.

[6] Nazanin-Samani M, Kamali AR, Mobarra R, Nazarian-Samani M. Phase transformation of Ni-15 wt.\% B powders during mechanical alloying and annealing. Mater Lett 2010;64:309-12. 